\title{
Defining Nature as a Common Pool Resource
}

Jonathan Rosenbloom ${ }^{1}$

I. Introduction

One of the many ways in which we attempt to study resource use and conservation is to define natural resources as "common pool resources." ${ }^{2}$ These are resources that are depletable and to which numerous common users maintain access in a rivalrous manner. Yet, the term "common pool resource" may be used to describe more broadly nature itself. ${ }^{3}$ Ultimately, humans engage in rivalry over the consumption of nature in which we share or pull from the same natural resources, which may certainly be depleted over time. Applying the common pool resource definition to nature incorporates several legal, societal, behavioral, and cultural concepts intended to capture the intricate and complex place where nature and the management of nature (or lack thereof) meet. That intersection involves the coming together of two very different systems: one, a dynamic, regionally diverse ecological system that includes many forms of natural capital, such as wetlands, forests, and water, and the other, a man-made, multi-jurisdictional, multi-layered system of governance that attempts to manage the use of that natural capital through legal rules and regulations. ${ }^{4}$ The common pool resource definition attempts to capture both the dynamic ecological system and the man-made system of rules and regulations, the complexity of the ramifications that stem from the intersection of these two systems, and the proper division of rights among those seeking to use natural capital.

Once we apply the common pool resource definition to nature, we commit to viewing nature through five distinct and specific lenses that are embedded in the common pool resource framework. This chapter explores these commitments in an effort to establish a foundation for related research on how these common pool resource-specific lenses may influence the management of nature. The chapter begins with a short background on common

\footnotetext{
${ }^{1}$ Associate Professor of Law, Drake University Law School. I would like to thank Professor Blake Hudson, Associate Professor, Joint Appointment, LSU Law Center and LSU School of the Coast and Environment, Baton Rouge, Louisiana for his perceptive and critical comments in helping properly frame and draft this chapter. I would also like to thank Professor Keith Hirokawa for letting me be a part of this book.

2 For purposes of this chapter, "natural resource" and "natural capital" are used indistinguishably to refer to various aspects of nature.

3 In the scholarly literature, the "common pool resource" definition is typically applied to distinct forms of natural capital, such as wetlands and forests, as opposed to nature more broadly. The intent of this chapter is not to challenge that application, but rather to embrace it by referring to "nature," as encompassing a wide variety of natural capital that has been and is defined as common pool resources.

${ }^{4}$ The common pool resource definition incorporates aspects of human behavior in relation to the appropriation or use of the natural capital. For purposes of this chapter, I frame the behavioral responses as reflections or reactions influenced by the governance structure or the lack of governance structure. This is not to suggest that the government structure is not influenced by or a response to appropriators' use of nature. Rather, in most cases the government structure and corresponding behaviors are constantly in flux and responding to each other.
} 
pool resources and the understanding of them in the legal literature. The chapter then turns to five conceptual commitments we make by labeling nature as a common pool resource. The commitments are not presented as positive or negative influences on the management of nature. Rather, they are descriptions of the choices we make and the implications of those choices by labeling nature as a common pool resource. The five commitments suggest that adopting a common pool resource framework for nature: i) contextualizes our relationship with nature as one of appropriation in which the most beneficial, if not the only, use of nature is to extract from or consume it, ii) limits the value of nature to an economic quantification of the natural resource to the exclusion of other environmental or social benefits, iii) recognizes that natural resources may be depletable, iv) confines management of natural resources to traditional property law doctrines and assumes preservation of natural capital can be achieved principally through anthropocentric management, and v) accounts for externalities and transboundary impacts.

The common pool resource definition allows us to identify and place a certain value on nature. The exploration of these commitments is an attempt to see if that value accurately reflects our understanding of nature. The goal of this chapter is to explore some of the intended and unintended consequences of labeling nature as a common pool resource and to begin to frame the larger question of whether the common pool resource structure is a beneficial method for understanding and managing the natural environment. ${ }^{5}$ An exploration of the commitments reveals that they have both intended and unintended consequences on the way we view nature. Those consequences, in turn, have both positive and negative implications for the management of nature. Further, regardless of whether the commitments help facilitate positive or negative approaches to nature management, each commitment places limiting and potentially harmful constraints on the broader perspective with which we should view nature. The chapter concludes by raising the question of whether this limited perspective fully considers pertinent characteristics inherent in nature and whether we should think more broadly when defining nature.

\section{Defining Common Pool Resources}

Commons scholars have identified two key characteristics that are inherent in common pool resources: depletability and non-excludability. ${ }^{6}$ Professor Oran Young described common

\footnotetext{
${ }^{5}$ This exploration into the commitments embedded in the common pool resource definition lays the groundwork for a forthcoming more in-depth analysis, detailing the implications these commitments have on the use and governance of nature.

${ }^{6}$ The aim of this section is to settle on an accepted definition of "common pool resource." The ultimate goal of this chapter is to develop an understanding what it means to apply that definition to nature.
} 
pool resources as resources "used by a group of appropriators that is both non-excludable and depletable."7 Similarly, professors Robert Keohane and Elinor Ostrom characterized common pool resources as "depletable natural or human-made resources from which potential beneficiaries are difficult to exclude." ${ }^{8}$ Professor Duncan Snidal stated that commons analysis "focuses on the provision and appropriation of goods that are not joint in consumption (like private goods) but where exclusion is difficult (like public goods)." ${ }^{9}$ As a simple illustration of a depletable and non-excludable resource, assume fisheries are labeled as a common pool resource. $^{10}$ Assume also that any fish caught or consumed by one fisherman is no longer available to the other fishermen. This illustrates the depletability of the resource. Further, the open nature and largeness of the ocean make it very difficult to exclude any one fisherman from continuing to consume the resource, exhibiting the non-excludability of the resource.

The act of consuming or using the common pool resource (such as catching a fish in the example above) is the act of "appropriation," while those who withdraw from a resource system (the fishermen in the example above) are "appropriators." ${ }^{11}$ The common pool resource itself is made up of "resource units," and it is "what individuals appropriate or use from resource systems." ${ }^{12}$ Resource units "are not subject to joint use or appropriation,"13 meaning that if a particular resource unit is being used or consumed by one appropriator it may not be appropriated by another. Appropriators can exclude other appropriators from a resource unit that has been appropriated, but not from the resource system and other resource units. In the fishery example above, the resource unit would be a fish, and the resource system, which we would call a "common pool resource," would be the fishery.

In the Tragedy of the Commons, ${ }^{14}$ Garrett Hardin described what he believed to be the inevitable result of allowing a common pool resource to be unregulated and not privatized.

\footnotetext{
7 Oran R. Young, Problem of Scale in Human/Environment Relationships, in LOCAL COMMONS AND GLOBAL INTERDEPENDENCE 27, 29 (Robert O. Keohane \& Elinor Ostrom eds., 1995) (emphasis added).

${ }^{8}$ Robert O. Keohane and Elinor Ostrom, Introduction, in LOCAL COMMONS AND GLOBAL INTERDEPENDENCE 1, 13 (Robert O. Keohane \& Elinor Ostrom eds., 1995) see also Daniel H. Cole \& Elinor Ostrom, The Variety of Property Systems and Rights in Natural Resources 5 (Sch. of Pub. \& Envtl. Aff., Ind. Univ., Research Paper No. 2010-08-01), available at http://ssrn.com/abstract=1656418 (citing VINCENT OSTROM \& ELINOR OSTROM, A Theory for Institutional Analysis of Common Pool Problems, in MANAgIng tHe Commons 157-72 (Garrett Hardin \& John Baden eds., 1977)) (noting that common pool resources are "large enough that it is costly to exclude potential beneficiaries ... ").

9 Duncan Snidal, The Politics of Scope: Endogenous Actors, Heterogeneity and Institutions, in LOCAL COMMONS AND Global INTERDEPENDENCE 47, 50 (Robert O. Keohane \& Elinor Ostrom eds., 1995).

${ }^{10}$ Ostrom and others have done so. See, e.g., ELINOR OSTROM, GOVERNING THE COMMONS: THE EVOLUTION OF INSTITUTIONS for Collective Action (1990); James M. Acheson, The Lobster GAngs of Maine (1988).

${ }^{11}$ Snidal, supra note 8. Ostrom gives numerous examples of appropriators, such as herders, fishers, irrigators, commuters, and "anyone else who appropriates resource units from some type of resource system." OstROM, supra note 10 , at 31 .

12 See id. at 30.

${ }^{13}$ Id. at 31.

${ }^{14}$ Garret Hardin, Tragedy of the Commons, 162 SCIENCE 1243 (1968).
} 
When confronted with an unregulated resource (also called an "open access" resource) each relevant actor on the commons (i.e. appropriators) maintains the right to use the commons resource as much as possible and has no ability to exclude other appropriators from doing so. ${ }^{15}$ Hardin theorized that the open nature of the commons allows each actor, or in the case above each fisherman, to make a rational calculation to continually consume the resource, or harvest the fish, in an effort to maximize personal economic gain. The rational actor will exploit the resource, Hardin stated, because he will gain the full benefit of utilizing the resource, but will externalize, or transfer, almost all of the detriment from his use of the resource across the entire pool of users. ${ }^{16}$ Upon making a "short-term cost-benefit analysis," each appropriator perceives himself in competition with the other appropriators and makes a "rational" decision to take as much of the resource as quickly as possible or risk suffering from the other actors' overuse of the resource. ${ }^{17}$ Without some coordinating force arising either internally from the collection of individuals or externally from an outside authority, the result, Hardin concluded, is destruction of the resource, as all actors will seek to improve their position and will over consume the commons resource. ${ }^{18}$

Particularly relevant to the labeling of nature as a common pool resource, Hardin also concluded that pollution is a type of appropriation that follows a similar tragedy of the commons trajectory. Polluters, Hardin observed, essentially consume the clean air resource. They gain the full benefit of producing something, but share the cost of disposing the waste stemming from that production (i.e. pollution) with all of the other actors. ${ }^{19}$ Thus, assume air is a common pool resource in which appropriators consume clean air by polluting the air, making

\footnotetext{
${ }^{15}$ An "open access" resource is significantly different from a "communal" resource. See Margaret A. McKean, Success on the Commons: A Comparative Examination of Institutions for Common Property Resource Management, 4 J. THEORETICAL POL. 247, 250-53 (1992) (defining "common property"); see also Acheson, supra note 9, at 143 ("As Bromley and a number of other authors have recently pointed out, there are really three different kinds of property: private property, communal or jointly owned property, and "open access.") (citation omitted); Robert C. Ellickson, Property in Land, 102 YALE L.J. 1315, 1322 (1993) (drawing a distinction between open access and communal ownership); Shi-Ling Hsu, A Two-Dimensional Framework For Analyzing Property Rights Regimes, 36 U.C. DAVIS L. REV. 813, 816-17 (2003) (same).

${ }^{16}$ Hardin, supra note 13 , at 1244 .

${ }^{17}$ Id. at 1244; see also H. Scott Gordon, The Economic Theory of a Common-Property Resource: The Fishery, 62 J. OF POL. ECON. 124, 135 (1954) ("Wealth that is free for all [to use] is valued by none because he who is foolhardy enough to wait for its proper time of use will only find that it has been taken by another.").

${ }^{18}$ Hardin, supra note 13, at 1244; see also OstROM, supra note 9, at 6 . Mancur Olson offered a similar perspective in 1965 in The Logic of Collective Action. See Mancur Olson, The Logic of Collective Action: Public Goods and the THEORY OF GROUPS (1965). Olson differs in one significant aspect from Hardin. Olson noted that the costs of collaborating, monitoring, and enforcing agreements among the participants may be reduced enough in small groups to make collaboration more efficient. Id. at 2, 43-45. But see Edella Schlager, Common-Pool Resource Theory in EnVIRONmental Governance ReConsidered: Challenges, Choices, AND OpPoRTunities 162-63 (Robert F. Durant et al. eds., 2004) (stating that research has not found a significant relationship between the likelihood of collaborative action and group numbers or area size).

${ }^{19}$ Hardin, supra note 13, at 1244.
} 
that resource unit of clean air no longer available to others. The polluter gains the benefit of not having to pay the full cost of controlling his pollution, and maintains the full benefit of producing something that resulted in the pollution. According to Hardin, each polluter is motivated to pollute as much as possible to the ultimate degradation of air quality.

Although common pool resources may arise in numerous contexts, its traditional application has been to natural capital. ${ }^{20}$ It has been used to establish a framework for understanding and assessing the management of resource units within a broad array of natural resource systems. Ostrom, for example, cited several natural resources as archetypal common pool resources, including fishing grounds, groundwater basins, grazing areas, streams, lakes, oceans, and other bodies of water. ${ }^{21}$ Similarly, Snidal noted that the "[s]tandard cases [of common pool resources] are natural resources, like forests or water."22 The common pool resource analysis, as applied to natural resources, has not only been prevalent in legal and political science literature, but also in judicial decisions. It has been cited by judges to help understand and describe the use of natural resources and project outcomes based on that usage, including in the areas of fisheries, water pollution, and public lands. ${ }^{23}$

\section{Five Commitments Embedded in Defining Nature as a Common Pool Resource}

Once we consider nature itself as a common pool resource, then it is difficult to separate our understanding of nature from our understanding of how common pool resources have been analyzed in the scholarly literature. Scholars have identified and assessed a number

\footnotetext{
${ }^{20}$ See, e.g., Millennium Ecosystem Assessment, World Health Organization, Ecosystems and Human Well-Being (2005) (cod fisheries); Intergovernmental Panel on Climate Change, Climate CHAnge 2007 - The Physical SCIence Basis (2008) (atmosphere); Nancy N Rabalais; R Eugene Turner; Donald Scavia, Beyond Science into Policy: Gulf of Mexico Hypoxia and the Mississippi River, Vol. 52, No. 2 BIOSCIENCE 129 (Feb 2002) (internal water sources).

${ }^{21}$ See OSTROM, supra note 9 , at 30.

${ }^{22}$ See Snidal, supra note 8, 47, 50; See also Michael Gochfeld, Joanna Burger, \& Bernard D. Goldstein, Medical Care as a Commons in PRotecting the Commons: A FrameWork for ResourCe MANAGEMENT IN THE AMERICAS 253 (2001) (citing common pool resource examples as good air quality, clean water, food production and others). The common pool resource framework has been extended to resources beyond the natural environment, including a variety of nontraditional commons resources, such as medical care, parking spaces, sidewalk vending, knowledge, government budgets, silence, email inboxes and even presidential primaries. Blake Hudson, Commerce in the Commons: A Unified Theory of Natural Capital Regulation under the Commerce Clause, 35 HARV. ENVTL. L. REV. 375 (2011) (citing Brigham Daniels, Governing the Presidential Nomination Commons, 84 TUL. L. REV. 899, 907 (2010)). In a recent article, Professor Blake Hudson and I argue that the institutions that facilitate inputs by society into chosen forms of governance also create a nested governance commons across levels of government. "One of the roles for which these systems of government have been developed, of course, is to manage natural resource commons. In this way, the governance commons is an overlay of natural resource commons. Stated differently, natural resource commons are embedded within the governance framework aimed at appropriating and managing those resources, which itself may be segmented in a way that tracks a commons." Blake Hudson, Jonathan Rosenbloom, Uncommon Approaches to Commons Problems: Nested Governance Commons and Climate Change, 64 HASTINGS L.J. (2013).

${ }^{23}$ Citizens Coal council v. U.S. Environ. Protection Agency, 385 F.3d 969 (6 $6^{\text {th }}$ Cir. 2004); Mausolf v. Babbitt, 85 F.3d 1295 ( $8^{\text {th }}$ Cir. 1996); Starbound, LLC v. Gutierrez, No. C07-0910-JCC , 2008 WL 1752219, (W.D. Wash. 2008).
} 
of characteristics of common pool resources, and human interactions with common pool resources. If we look at nature through those same lenses, then it may result in an unintended, and perhaps even detrimental, under-appreciation of nature's unique qualities. To understand the relevance of labeling nature as a common pool resource, this section explores five distinct and specific commitments that are embedded within the common pool resource definition. The objective is to provide a more detailed understanding of what assumptions are incorporated into the common pool resource definition, and to lay a foundation for exploring whether those assumptions are beneficial for understanding and sustainably managing the natural environment.

\section{i. Appropriation}

Embedded in the definition of common pool resource is an assumption that human interaction with and appreciation of nature is primarily one of appropriation, where humans consume the resource. Pursuant to the accepted definition of and scholarship on common pool resources, the predominant manner in which actors engage a resource, or what Hardin would describe as rationally act in relation to a resource, is understood in terms the actors' use, consumption, or deterioration of the resource. The actors' primary, and often singular, objective is to consume the resource (and often to consume it at a rate faster than the other actors). Any rational actor, it is assumed, would want to use or appropriate from the resource, as it will improve their position; and there is little place for non-appropriative human interaction with the resource.

While appropriation or consumption of nature may accurately describe our predominant interaction with it, applying the common pool resource definition to nature seems to limit the ways in which we might interact or benefit from nature. It does not fully account for, or even acknowledge, that humans may interact with nature in a number of ways. In fact, some may not wish to appropriate from nature at all. The definition fails to account for human's appreciation of nature as, for example, something vital to our existence. Further, in some circumstances "rational" actors may be motivated to preserve or add to - and not consume - nature for a variety of reasons including, to promote human development (such as, health). ${ }^{24}$ Similarly, the definition does not acknowledge that many people find physical and

\footnotetext{
${ }^{24}$ It is hard to imagine, for example, the Inuit culture focusing solely on appropriation as a means of defining nature. See Inuit Petition to the Inter-American Commission on Human Rights (2005), http://www.inuitcircumpolar.com/index.php?Lang=En\&ID=316 (last visited Sept. 3, 2012). See also National Research Council, Sustainability and the U.S. Environmental Protection Agency 1 (Nat'I Acad. Press 2011):

Everything that humans require for their survival and well-being depends, directly or indirectly, on the natural environment. The environment provides the air we breathe, the water we drink, and the food we eat. It defines in fundamental ways the communities in which we live and is the source for renewable and nonrenewable resources on which civilization depends. Our health and well-being, our economy, and our security all require a high quality environment.
} 
psychological benefits from the aesthetic beauty of nature, and that consumption or appropriation of nature is antithetical to the continued benefits stemming from it.

Appropriation, as understood and incorporated into the common pool resource scholarship, occurs in a single, isolated resource system. When one actor appropriates a resource unit, the common pool resource definition views that appropriation solely within the confines of the individual resource system. As an example assume a resource system is coastal land and that the development of coastal lands is an appropriation of a resource unit (individual parcels of land). Extending Hardin's analysis to this application reveals that rational developers will want to develop the land as quickly as possible and as much as possible. Hardin's analysis, however, does not account for the effects appropriation within this resource system (i.e. development) will have on other resource systems, such as water (affecting flooding through increased run-off or destruction of natural coastal barriers), biodiversity (increasing likelihood of extinction through removal of habitat or travel lanes), or air quality (affecting climate change through the removal of carbon sinks like wetlands). The common pool resource definition does not account for externalities occurring outside the resource system and experienced in other resource systems. As described further below, the common pool resource definition accounts for externalities to other actors, but those actors are operating within the same resource system.

When applied to nature, this isolation of common pool resources fails to fully capture nature's behavior. Many forms of natural capital are interdependent on other forms of natural capital. Because the common pool resource definition tends to isolate natural capital and views appropriation as having occurred in a vacuum, the definition misses an essential characteristic of nature, namely, its interconnectedness. Because the definition does not recognize this aspect of nature, it has little problem applying to a broad spectrum of issues - natural and manmade - from wetlands to parking spaces. Applying the same term to help define wetlands or parking spaces is to overlook the symbiotic characteristics and interactions between numerous natural capital resources and even overlapping forms of human-made capital. ${ }^{25}$

\section{ii. Economic Quantification}

Implicit in defining nature as a common pool resource is that the actors are motivated to appropriate the resource because there is an economic value associated with such appropriation. It is assumed that the actors perform a short term economic quantification that encourages them to appropriate the resource. This aspect of the common pool resource

\footnotetext{
${ }^{25}$ I should also note that appropriation is understood as happening here and now. There is little concern or space to consider inter-generational appropriation. For a discussion of intergenerational equity see EDITH BROWN WEISS, IN FAIRNESS TO FUtURE GENERATIONS: INTERGENERATIONAL LAW, COMMON PATRIMONY AND INTERGENERATIONAL EQUITY 36-39 (1998).
} 
definition differs from the identification of "appropriation" in the first subsection, as this portion of the definition explores why the actors appropriate. The first subsection denotes appropriation as the key interaction between humans and nature, but it does not explain the motivation behind the actors' appropriation.

As Hardin stated, a rational actor understands that appropriation of a resource unit will result in the actor "receiv[ing] all the proceeds from the sale of [the unit]." ${ }^{26}$ Further, the actor shares the "negative utility" or detriment of extracting that resource unit with all of the other actors. According to Hardin, it is this individual economic quantification of receiving all of the benefit and sharing the detriment that sufficiently motivates the rational actor to consume the resource.

In the context of nature, the common pool resource definition assumes that economic benefits are the key motivating factor that encourage humans to consume (or, as stated in subsection i, "appropriate") nature. This assumption overly limits the spectrum of factors or reasons why one would appropriate nature. Pursuant to the common pool resource scholarship, the most important - and potentially the sole - factor why one would appropriate nature is an economic valuation of appropriation of the resource. There is little room for expanding or calculating other factors, including environmental or social factors that may involve health, social justice, and equity issues. The failure to recognize non-economic motivators that could encourage appropriation, such as those stemming from the environment, is amplified because the essence of the resource system being labeled a common pool resource is the natural environment. ${ }^{27}$

An understanding of why actors appropriate from some non-nature based common pool resources is informative to demonstrate how the economic profit derived from appropriation may be the sole purpose of appropriating the resource. For example, an economic analysis encapsulates the essence and core purpose of some non-nature based common pool resources, such as sidewalk vending licenses or local economic development. ${ }^{28}$ These common pool resources function primarily to facilitate economically driven activities. The same is only partially true about many aspects of nature. When nature is labeled as a common pool

\footnotetext{
${ }^{26}$ Hardin, supra note 13 , at 1244 .

${ }^{27}$ Professor Hudson pointed out that maybe appropriation itself is not too limiting of a factor, but rather the perspective on what is being appropriated is too narrow. Because there would be an economic cost to not appropriating a resource (for health considerations, for example), then that could be interpreted as a type of appropriation. In other words, the preservation of clean air and the prevention pollution for health reasons could also be viewed or analyzed as an act of appropriation in the foregone economic benefit that would have resulted from the pollution.

${ }^{28}$ Michael Gochfeld, Joanna Burger, \& Bernard D. Goldstein, Medical Care as a Commons in PROTECTING THE COMmons: A FRAMEWORK FOR ResourCe MANAgEMENT IN THE AMERICAS 253 (2001) (citing vending licenses, local economic development and other non-nature based common pool resources).
} 
resource, it is assumed an economic analysis will facilitate an understanding of how actors will engage the resource and the value they get from the resource. At best, however, an economic analysis provides only a partial snapshot of the true value of the natural resource. For starters, it does not accurately reflect the environmental value of the resource. The economic quantification establishes a very limited dialog between humans and the resource and pays little heed to the larger scientific or ecologic impacts of appropriation or alternative values of the resource. ${ }^{29}$ For example, a straightforward economic analysis of a polluter discharging into the atmosphere will not provide the necessary information to explain the environmental or social harms stemming from the pollution, including impacts to flora and fauna, even though these "non-economic" harms may be deeply connected and more relevant to the survival of the resource and the relevant actors.

\section{iii. Depletable}

Incorporated into the definition of common pool resource is that the resource is depletable. Hardin illustrated depletability by explaining how herdsmen would operate on an open pasture:

$[T]$ he rational herdsman concludes that the only sensible course ... is to add another animal to his herd. And another; and another.... But this is the conclusion reached by each and every rational herdsman sharing the commons. Therein is the tragedy. Each man is locked into a system that compels him to increase his herd without limit - in a world that is limited. Ruin is the destination toward which all men rush ....

Characterizing the theoretical inevitable results of having an open access common pool resource, Hardin recognized that common pool resources are limited and that if left unsustainably managed actors will consume and destroy their respective resources.

In the context of nature, recognizing depletability and possible complete destruction of the resource is critical because it acknowledges that natural capital is limited, can be extinguished, and, when left unmanaged, will be consumed to its "[r]uin." By incorporating depletability, the common pool resource definition accounts for the fragility of nature. It notes that nature is finite and absent-minded consumption of it can have long-lasting negative effects. Relatedly, the common pool resource definition recognizes that if that fragility is not accounted for and managed properly, the resource will be destroyed.

Defining the atmosphere as a common pool resource provides an example of how depletability and potential destruction helps explain important characteristics inherent in

\footnotetext{
${ }^{29}$ Some scholars have argued for the incorporation of environmental and/or social costs into an economic costbenefit analysis, which would broaden the motivating factors relevant to understanding appropriation.
} 
nature. Once the atmosphere is labeled as a common pool resource, it is acknowledged that it can be consumed. Further, unmanaged consumption of it may lead to its destruction. As prior authors have stated, the atmosphere is, in large part, an unregulated common pool resource. ${ }^{30}$ It freely flows in and out of national jurisdictions, and cannot be confined to one country's regulation. As a partially unregulated resource, the common pool resource definition suggests that actors are motivated to consume it and that this consumption will lead to its ultimate destruction. One form of consuming the atmosphere is the disposal of waste or the emission of air pollution into the atmosphere. ${ }^{31}$ "Given that the atmosphere cannot be fenced or parceled into shares, 'individuals, companies, and states . . . [will tend] to 'free-ride' by letting others take on the costs of mitigat[ing]' the impacts of their pollution (in the form of carbon emissions) 'while they continue to enjoy the benefits of those activities. ...'”32

Following Hardin's analysis to its conclusion, actors are motivated to continue to emit carbon emissions, which will lead to ruin of the atmosphere - or global warming and ensuing climate change. Because the common pool resource definition takes note that the continued unmanaged consumption of a resource can lead to a complete loss of the resource, there is an implication that a limit exists to how much carbon dioxide the atmosphere can absorb before deterioration begins. Also pursuant to the definition, actors will continue to emit carbon dioxide into the atmosphere so long as air remains an open access resource, despite the ramifications this is having on the atmosphere and its contribution to global warming. Pursuant to the definition (and as many scholars and scientists have argued), the continued appropriation from the resource will not only lead to destruction of the atmosphere (the relevant resource system), but also to drastic changes in the broader ecological system.

The common pool resource definition, at a minimum, recognizes that nature has limits. Surpassing those limits has consequences that include a total loss of the resource. When we label wetlands, forests, or biodiversity as common pool resources, we acknowledge that there are inherent limited capacities. Further, this limited capacity makes tangible an understanding that completely consuming (or polluting) the resource will result in exceeding that capacity and a total loss of the resource. Of course, having that knowledge does not equate with seeking to

\footnotetext{
30 John Vogler, The Global Commons: Environmental and TeChnological Governance 105 (2d ed. 2000); Sarah Krakoff, Planetarian Identity Formation and the Relocalization of Environmental Law, 64 FLA. L. REV. 87 (2012); Robert DeLay, Our Post-Kyoto Treaty Climate Change Framework: Open Market Carbon-Ranching as Smart Development, 7 Penn. St. EnVTL. L. Rev. 55, 67 (2008); J.R. DeShazo \& Jody Freeman, Timing and Form of Federal Regulation: The Case of Climate Change, 155 U. PA. L. REV. 1499, 1518-19 (2007) (describing global warming as a collective action challenge that raises tragedy of the commons issues).

${ }^{31}$ Christopher Joyner, Global Commons: The Oceans, Antarctica, the Atmosphere, and Outer Space in MANAGING GLOBAL IsSUES: LESSONS LEARNED 354, 361 (P.J. Simmons \& Chantar de Jonge Oudraat eds., Carnegie Endowment for International Peace 2001).

${ }^{32}$ Patrick Wieland, From Kyoto to Quito: Reassessing Oil Moratorium as an Effective Climate Change Policy from a Property-Based Approach, 4 KY. J. EqUINE, AGRIC. \& NAT. RESOURCES L. 93, 117 (2011-2012) (footnotes omitted).
} 
preserve the resource or avoid a tragic consumption of the resource (as we have seen in the climate change debate), but if the definition of nature did not recognize limits to the resource, there would be little or no discussion of restricting or reducing consumption of the resource. The common pool resource definition allows us to better structure responses to avoid unsustainable outcomes because the definition considers the limitations of nature. Viewed through this framework we can make better management decisions based on some of the true characteristics of nature - namely, that it is a finite resource.

\section{iv. Traditional Property Law Doctrines and Anthropocentric Management}

In the United States, defining nature as a common pool resource subjects nature to traditional property law doctrines. Historically, the property law approach to the division of rights followed a categorization of the resource rights as "private" and/or "public." As Hardin stated, when confronting a common pool resource: "We have several options. We might sell [the resource] off as private property. We might keep [it] as public property, but allocate the right to enter [it]." Distinguishing between public and private property incorporates an application of the Rule of Capture. As discussed by Professor Hirokawa in the introduction to this book, the Rule of Capture recognizes protected private property rights upon the actors successfully achieving some level of possession over the resource.

Confining the definition of nature to property law doctrines and the Rule of Capture treats all common pool resources - natural and otherwise - the same regardless of their unique qualities or the risks associated with resource depletion. The Rule of Capture, for example, does not differentiate among resources and does not account for the external impacts stemming from the appropriation of those resources. The Rule is applied equally whether appropriation is sought over nature or an inanimate object, such as a baseball. ${ }^{33}$ Applying the Rule of Capture and other property law doctrines to nature and how we interact with nature renders the specific characteristics of nature almost meaningless, as the Rule of Capture does not fully consider how nature evolves and adapts, and is fundamental to our existence. A good example can be found in many water rights decisions in the U.S., such as:

The fallacy which seems to have operated upon the mind of the joint board and of its engineer is one we encounter not infrequently; that is, that a landowner is under some continuing obligation to 'pay the freight' upon his own surface waters after they have left his lands and until they reach an ultimate outlet. . . On the contrary, he may freely avail himself of the topography of his land, and may discharge his surface waters wherever gravitation naturally carries them,

\footnotetext{
${ }^{33}$ See Popov v. Hayashi, 2002 WL 31833731 (Dec. 18, 2002) (applying the Rule of Capture to the dispute over Barry Bond's 73 homerun baseball).
} 
without further concern on his part as to where they go, for they are no longer his. There is no final outlet for the surface waters of this state this side of the gulf. . . . by the same logic it could be charged with benefits in the construction of the jetties at the mouth of the Mississippi. ${ }^{34}$

This decision and others like it treat common pool resources the same. They, as extensions of the common pool resource definition, ignore characteristics that make nature unique and vital.

Additionally, a property rights based approach limits the options available to manage nature. Pursuant to common pool resource scholarship, property law helps articulate one of four available options to manage common pool resources to avoid a tragedy of the commons: ${ }^{35}$ (1) regulation by a higher level of government, (2) privatization of property rights in the resource, (3) individual self-regulation, and (4) self-coordinated collaboration among the

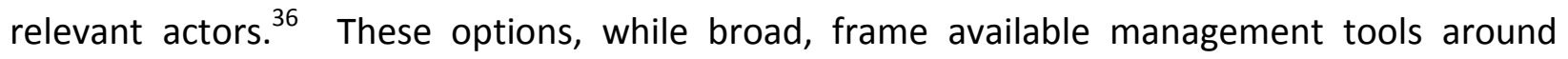
anthropocentric ideas of property rights and how nature must be managed. They do not provide management options based on characteristics that are inherent in nature. As new scientific discoveries alter our understanding of nature, we may seek management options that more closely address changing environmental conditions and that more accurately reflect nature itself. New alternatives may go beyond the current property law options and incorporate more environmentally based aspects, such as an ecosystems approach, to capture the true environmental conditions relevant to the management and understanding of nature. ${ }^{37}$

\section{v. Externalities and Transboundary Impacts}

The final commitment implicit in the common pool resource definition is the notion that one actor's consumption of a resource unit has externalities on other actors in the same resource system. Further, those actors need not be confined to the same legal jurisdictional boundaries, although they must be actors within the same resource system. When one actor appropriates a resource unit from an unregulated resource system, he internalizes the benefit of that appropriation, but he externalizes the detriment or negative effects of that appropriation. $^{38}$ In addition, those effects are measured by the impacts in the resource system

\footnotetext{
${ }^{34}$ Ohrtman Revocable Trust v. Palo Alto Cty. Bd. of Supervisors, 760 N.W. 2d 210 (IA Ct. of Apps. 2008).

${ }^{35}$ Most common pool resource management is a hybrid of the four forms. See Cole \& Ostrom, supra note 7, at 10.

${ }^{36}$ Jonathan Rosenbloom, New Day at the Pool: State Preemption, Common Pool Resources, and Non-Place Based Municipal Collaborations, 36 HARV. ENVIRON. L. R. 446, 462-68 (2012).

${ }^{37}$ Several scholars have proposed innovative ecosystem services solutions to common pool challenges including T.H. Tietenberg, Emissions Trading: Principles and Practice (2006) (system of fungible pollution permits); Floor Brouwer, Philip Lowe, Cap Regimes and the European Countryside: Prospects for Integrations betWeen Agricultural, REgIONAL AND ENVIRONMENTAL PoliCIES (CABI 2000) (proposing ecosystem service-based subsidies for agriculture).

${ }^{38}$ Hardin asked "'What is the utility to me of adding one more animal to my herd?'" and explained:
} 
and not the jurisdictional boundaries. By acknowledging that actors affect each other through appropriation, the common pool resource definition recognizes that the resource is shared by many actors and that those actors are intricately connected through the use of the resource system. It also recognizes that the actors face common risks associated with the consumption of the resource.

The acknowledgement that actors affect one another and share a common fate has important consequences for understanding nature. It accounts for the fact that many forms of natural capital are shared by many people in multiple jurisdictions simultaneously. It acknowledges that when one actor consumes a natural capital resource unit it has negative effects on other actors who rely on the same resource system, regardless of where they are geographically located. Those actors may be thousands of miles apart and in different jurisdictions. For example, assume the Mississippi River is labeled a common pool resource, and appropriation from the resource occurs through pollution. The common pool resource definition implicitly recognizes that when nitrogen and phosphorous stemming from Midwest farms' use of fertilizer washes into the Mississippi River the farmers are appropriating a resource unit. $^{39}$ The resource unit they are appropriating is clean water from the resource system. The farmers fully internalize the benefit of their appropriation, as they are not required to pay for the proper disposal or containment of the nitrogen and phosphorous. The common pool resource definition also recognizes that the detriment of the discharge is shared with all of the other actors utilizing the Mississippi. Downstream actors including those seeking potable water or those fishing in the Mississippi or the Gulf of Mexico bear the cost of the upstream actors' appropriation. That cost includes making the water suitable to drink and reducing fisheries in the River and the Gulf of Mexico through the growth of hypoxic areas. ${ }^{40}$

In the context of nature, the acknowledgement that common pool resource actors have an impact on each other helps reflect the interconnected elements of nature. Ostrom believed it was the actors' understanding that they are locked together and would succumb to a disastrous fate that could motivate them to voluntarily collaborate (in lieu of a tragedy of the

This utility has one negative and one positive component. 1) The positive component is a function of the increment of one animal ... the positive utility is nearly +1 . 2) The negative component is a function of the additional overgrazing created by one more animal. Since . . the effects of overgrazing are shared by all the herdsmen, the negative utility for any particular decision-making herdsman is only a fraction of -1 .

Hardin, supra note 13, at 1244.

${ }^{39}$ See National Oceanic and Atmospheric Administration, US Dep't of Commerce, Dead Zones, Hypoxia in the Gulf of Mexico (July 2009) ("Seventy percent of nutrient loads that cause hypoxia are a result of agricultural runoff of [Mississippi] basin.").

${ }^{40}$ Nitrogen and phosphorous create a source of nutrients for phytoplankton. The phytoplankton is then fed on by zooplankton. When the phytoplankton decompose and the zooplankton produce waste, oxygen in the water drastically reduces, leaving little ability for life, including fisheries, to exist. See National Oceanic and Atmospheric Administration, US Dep't of Commerce, Dead Zones, Hypoxia in the Gulf of Mexico (July 2009). 
commons, regulatory authority, or private property rights) and self-regulate their consumption to avoid ruin of the resource-under a particular set of circumstances at least. ${ }^{41}$ The common pool resource definition helps to identify the relevant actors that appropriate from nature and how their behavior affects other actors. It defines the actors based on the resource system, as opposed to geographical or political boundaries, thereby, providing more insight into who the relevant parties are.

By acknowledging the far reaching effects of consuming nature, the common pool resource definition theoretically allows for the consideration of natural resource management beyond jurisdictional boundaries. It opens the door to an ecosystems management approach to nature, as it is the system that guides who is affected by it and not geographical jurisdictional boundaries. This could have a positive effect on the manner in which we manage nature, as it more accurately reflects nature. However, while the definition incorporates multi-jurisdictional externalities, it does not require that these externalities be addressed in a sustainable manner. In fact, most, if not all, options concerning common pool resource management tend to be biased towards the property based rights described in subsection iv above, disregarding externalities.

Conclusion

The implications of defining nature as a common pool resource are as stark as Hardin's projections as to where an unregulated common pool resource will lead. The common pool resource definition is embedded with five preconceived commitments that have implications on the way we understand nature. Together these commitments are designed to help explain the complex and diverse systems of nature and the management of nature. They simplify the moment where these two systems meet, and inform our understanding of the traditional and predominant relationships we have with nature. The attempt of this chapter was to isolate and dissect the five commitments in the context of nature. As implied above, sometimes the commitments help encourage positive and sustainable management of nature through collective action, privatizing rights, or regulation. Sometimes, however, they also encourage the tragic management of nature, such that it is over-consumed. The exploration in this chapter begins to reveal that even when the commitments result in the positive and sustainable management of nature, the path they take to getting there assumes a narrow or particular view of nature.

This chapter undertakes a constructivist exercise to observe the various commitments embedded in the common pool resource definition that help simplify the two complex systems of nature and the management of nature. But the use of the common pool resource definition

\footnotetext{
${ }^{41}$ See Ostrom, supra note 13.
} 
is not a certainty. The next (and critical) step is to go beyond the constructivist exercise and to determine whether the narrow common pool resource view accurately reflects nature and its importance. In other words, do the commitments properly value nature's attributes? We see what the commitments give us; the next question is do we like what we see? Answering this question includes determining whether the common pool resource definition captures the critical aspects of nature and how we want to understand nature. And, perhaps most importantly, do the definition and the implications discussed in this chapter help us make informed decisions to sustainably manage nature for future generations in a way that gives us a better world? 